Discussion Paper No. 01-65

Contraction of Global Carbon Emissions:

How Acceptable Are Alternative Emission Entitlement Schemes?

Christoph Böhringer and Heinz Welsch

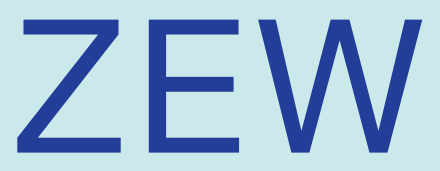

Zentrum für Europäische Wirtschaftsforschung GmbH

Centre for European Economic Research 
Discussion Paper No. 01-65

\title{
Contraction of Global Carbon Emissions: How Acceptable Are Alternative Emission Entitlement Schemes?
}

\author{
Christoph Böhringer and Heinz Welsch
}

Download this ZEW Discussion Paper from our ftp server:

ftp://ftp.zew.de/pub/zew-docs/dp/dp0165.pdf

Die Discussion Papers dienen einer mŏglichst schnellen Verbreitung vou neueren Forschungsarbeiten des ZEW. Die Beiträge liegen in alleiniger Verantwortung der Autoren und stellen nicht notwendigerweise die Meinung des ZEW dar.

Discussion Papers are intended to make results of ZEW research promptly available to other economists in order to encourage discussion and suggestions for revisions. The authors are solely responsible for the contents which do not necessarily represent the opinion of the ZEW. 


\section{Non-technical summary:}

The allocation of emission entitlements across countries is the single most controversial issue in international climate policy. Extreme positions within the policy debate range from entitlements based on current emission patterns $(C E P)$ to equal-per-capita $(E P C)$ allocations. Convergence $(C O V)$ from an initial $C E P$ allocation towards $E P C$ emission rights represents a reconciliation of the two. This paper maintains that the acceptability of alternative entitlement schemes depends on their implications for economic welfare. Based on a dynamic multisector, multi-region general equilibrium model of the world economy we do a comparative economic assessment of the above allocation rules.

We find that - independent of emissions trading - CEP can be assessed as unacceptable to the developing countries since it imposes high welfare losses on them. Concerning the EPC scheme, the most outstanding result is that, unless coupled with emissions trading, it entails global welfare costs several times higher than those encountered under the other entitlement rules. The extreme dispersion of marginal abatement costs implied by the EPC arrangement offers a large potential for cost reduction by means of international emissions trading. The latter will cut global welfare costs by 80 percent and would provide a Pareto improvement over the corresponding no-trade case. EPC cum emissions trading, however, induces a pronounced dichotomy between the developing countries and the industrialized countries in that the former experience welfare gains relative to the doing-nothing case, whereas the latter would must carry the burden not only of climate change mitigation but also of large-scale global income redistribution. COV cum emissions trading stands out for offering the developing countries substantial incentives for participation in the international greenhouse gas abatement effort without imposing excessive burdens on the industrialized countries. Thus - among the arrangements examined - COV cum emissions trading appears as the most acceptable.

In addition to the policy perspective, a major methodological insight from our results is that changes in the terms of trade play an important role in assessing the economic implications of alternative frameworks for international greenhouse gas abatement. Terms-oftrade effects may imply that a particular emission entitlement scheme places significant welfare costs even on those countries that do not face binding emission constraints. Therefore, the acceptability of alternative international carbon abatement arrangements cannot be assessed at "face value". 


\title{
Contraction of Global Carbon Emissions: How acceptable are alternative emission entitlement schemes?
}

\author{
Christoph Böhringer $^{\mathrm{a}}$ and Heinz Welsch ${ }^{\mathrm{b}}$
}

\begin{abstract}
The allocation of emission entitlements across countries is the single most controversial issue in international climate policy. Extreme positions within the policy debate range from entitlements based on current emission patterns $(C E P)$ to equal-per-capita $(E P C)$ allocations. Convergence $(C O V)$ from an initial $C E P$ allocation towards $E P C$ emission rights represents a reconciliation of the two. This paper maintains that the acceptability of alternative entitlement schemes depends on their implications for economic welfare and uses a dynamic multi-region general equilibrium model for a comparative economic assessment of the above allocation rules. We find welfare implications for the various regions to be strongly influenced by changes in the terms of trade. Especially, regions may experience considerable welfare losses even under entitlement schemes which impose no binding emission constraint on them. Among the arrangements examined, $\mathrm{COV}$ cum emissions trading stands out for offering the developing countries substantial incentives for participation in the international greenhouse gas abatement effort without imposing excessive burdens on the industrialized countries.
\end{abstract}

Key words: climate policy, economic welfare, international equity, emissions trading, computable general equilibrium modeling.

JEL classification: Q2, Q4, D58

\footnotetext{
${ }^{a}$ Centre for European Economic Research (ZEW), Mannheim, Germany, boehringer@zew.de

${ }^{\mathrm{b}}$ University of Oldenburg, Oldenburg, Germany, welsch@uni-oldenburg.de
} 


\section{Introduction}

In order to mitigate the expected climate change arising from the atmospheric accumulation of $\mathrm{CO}_{2}$ and other trace gases, a significant contraction of global greenhouse gas emissions is widely postulated. The Intergovernmental Panel on Climate Change (IPCC) has stated that in order to avoid a substantial increase of the global mean temperature by the end of the 21st century, global emissions will have to be reduced by up to one half by 2100 (UNEP 2001).

International policy agreements to achieve such reduction targets must - in the first place - address one fundamental issue which has already dominated previous climate change negotiations and which proved to be extremely difficult to solve: the allocation of emission entitlements or likewise abatement duties across countries. A second, related issue is the flexibility with which these duties can be fulfilled by the countries involved, for instance by means of international emissions trading. Whether emission entitlements should be tradable or not is also subject to controversy in the political arena. ${ }^{1}$

Proposals on the allocation of emission entitlements can be grouped in terms of two main focal principles (Grubb 1995): equal per capita allocation and allocation related to the status quo. The equal per capita allocation corresponds to the justice principle of "equality of resources" and is the fair division criteria most often cited in the literature (see Bertram 1992, Kverndokk 1995). It is derived directly from egalitarianism, suggesting that all human beings should be entitled to an equal share of the atmospheric resource. At the opposite end of the spectrum, a strict status-quo allocation - proportionate to current emissions - has been considered in the literature (see e.g. Young and Wolf 1992). According to this view, current emissions would constitute a status-quo right established by past usage and custom.

These two principles mark the range of positions held by the players in international climate diplomacy. Many developing countries have emphasized that acceptance of any emission constraint can be expected only if emission rights are allocated on an equal-percapita basis (Rose et al. 1998). From the perspective of the industrialized countries, however, equal per capita entitlements would imply a tremendous deviation from current emission

\footnotetext{
${ }^{1}$ Objections against international emissions trading range from moral considerations to pragmatic ones. Moral arguments - which play a role in the policy debate although typically neglected from a purely economic point of view - maintain that emissions trading allows countries "to buy themselves out" of their obligations. Pragmatic aspects concern the certification, verification and monitoring of international emissions trading. Even though diverging views on the role of flexibility played a role in the climate policy negotiations so far, it is essentially the controversy about the allocation of abatement duties between industrialized and developing countries which led to the recent withdrawal of the U.S. from the Kyoto Protocol.
} 
patterns and - if applied on short notice - induce huge adjustment costs in the countries with currently high per capita emissions.

In view of the latter consideration, it is, therefore, reasonable to interpret the egalitarian criterion in a long-term perspective, allowing for gradual adjustment from current emission patterns towards a terminal point where future entitlements to emit will have become proportional to population (convergence). The global emission budget in such a scenario would have to be continuously reduced, in line with the climate protection requirements mentioned above. ${ }^{2}$

Convergence of emission entitlements appears to be a natural way of reconciling the two extreme normative positions discussed above. It is essentially a mixed system which links egalitarian and status-quo approaches by combining population and current emissions such that the weighting accorded to population increases over time towards a purer per capita allocation.

This paper maintains that irrespective of the comparative philosophical appeal of the three fundamental approaches to emission entitlement, the prospects for a broader political agreement on any one approach will depend on their economic implications in terms of the magnitude and distribution of welfare costs across regions. ${ }^{3}$ Assessment of these implications is, however, a complex task, especially because the welfare costs of emission abatement depend not only on the profile of emission entitlements but also on whether emission entitlements are tradable or not.

In approaching this problem, we use a dynamic multi-region general equilibrium model of the world economy to provide a comparative economic assessment of the emission entitlement schemes outlined above. Each of these entitlement scenarios is examined for the case with and without emissions trading among the regions.

A major methodological finding of the paper is that the welfare implications for the various regions are strongly influenced by changes in the terms of trade. Because of this influence, some regions may experience significant welfare losses even under entitlement allocation rules which impose no binding emission constraint on them. In addition, terms of trade effects may prevent that international emissions trading provides a Pareto improvement relative to a no-trade regime. In view of such effects, it becomes obvious that alternative

\footnotetext{
${ }^{2}$ Formulations such as this have been discussed independently by Grubb and Sebenius (1992), Shue (1993) and Welsch (1993). More recently, a similar proposal has been launched under the label "Contraction and Convergence" (Global Commons Institute 1997).

${ }^{3}$ Our welfare evaluation deliberately neglects the benefits from global warming mitigation, since benefit estimates are highly uncertain and therefore can be expected to have little influence on the acceptability of emission entitlement schemes.
} 
greenhouse gas abatement arrangements cannot be assessed at face "value". We find that, among the arrangements examined, the convergence approach coupled with emissions trading has substantial comparative virtues by offering the developing countries incentives for participation in the international greenhouse gas abatement effort without imposing excessive burdens on the industrialized countries.

The paper is organized as follows. Section 2 provides the definition of the stylized policy frameworks to be examined. Section 3 outlines the characteristics and parameterization of the model employed, and section 4 presents the numerical results. In section 5 , we discuss the results obtained and suggest policy conclusions.

\section{Design of Abatement Policies}

We consider three emission entitlement rules each of which is combined with two alternative assumptions on the tradability of emission rights. This yields six scenarios to be examined.

\section{A. Alternative Distribution Rules for Emission Entitlements}

In our policy simulations we compare three alternative assumptions on the entitlement to carbon emissions:

CEP Current Emission Patterns: The global carbon resource is distributed across regions in proportion to their current emissions.

EPC Equal Per Capita: The global carbon resource is distributed across regions in proportion to their respective population.

$C O V$ Convergence: As compared to $C E P$ and $E P C$, the convergence scenario requires an explicit consideration of the time horizon. Starting from the present, where current emission patterns define the emission entitlement, $C O V$ warrants a gradual convergence of emission entitlements over a specified time horizon towards equal-percapita rights (see section 2B below).

Scenarios $C E P$ and $E P C$ cover extreme positions in the equity debate while $C O V$ represents a reconciliation of the two. 


\section{B. Definition of Global Emission Trajectory}

Having stated the basic distribution rules for emission entitlements, we next define the global carbon emission constraint over time. We refer to requests by the Intergovernmental Panel on Climate Change (IPCC) which postulates a reduction of global carbon emissions till 2100 by up to 50 percent below current levels (UNEP 2001). We take this to mean that emissions till 2050 are to be reduced by roughly 25 percent and that this target is to be attained by gradual adjustment of global emissions over the period 2010 to $2050 .^{4}$

The global emission trajectory over the adjustment period is obtained by merging the global reduction target for 2050 with the idea of convergence of per capita entitlements towards the target year. This yields a gradual adjustment in both total emissions and in the distribution of emission rights across countries.

In formal terms, the convergence idea warrants that the per capita emission rights of country $i$ in year $t, z_{i}(t)$, are a weighted average of business-as-usual per capita emissions in 2010 and the uniform per capita right $\bar{z}$ valid in 2050:

$$
\mathrm{z}_{\mathrm{i}}(\mathrm{t})=\frac{40-(\mathrm{t}-2010)}{40} \cdot \mathrm{z}_{\mathrm{i}}(2010)+\frac{(\mathrm{t}-2010)}{40} \cdot \overline{\mathrm{z}}
$$

The total carbon limit $C A R B L I M_{i}(t)$ for a country in a certain year is obtained by multiplying the per capita emission right by the country's population $P O P_{i}(t)$ in that year ${ }^{5}$ :

$$
\operatorname{CARBLIM}_{i}(t)=z_{i}(t) \cdot P O P_{i}(t)
$$

Adding the carbon limits across countries defines the global carbon limit over the time horizon. We impose this global emission trajectory also on the scenarios $C E P$ and $E P C$ to assure consistent comparison of alternative carbon entitlement rules. Under $C E P$, the given global carbon budget at any point in time will be distributed across regions in proportion to their 2010 emission levels whereas under EPC the carbon emissions will be allocated proportional to the regions' projected population.

\footnotetext{
${ }^{4}$ The choice of 2010 as the starting year for global emission reduction reflects the idea that some time will be needed to achieve such a substantial international agreement and that its provisions will not enter into force instantaneously.

${ }^{5}$ Of course, in implementing this formula, it is important to use population projections fixed ex ante, in order to avoid incentives for population growth.
} 


\section{Flexibility}

We distinguish between two abatement regimes which capture the extreme points of where-flexibility ${ }^{6}$ in international carbon abatement policy:

- NTR: The carbon limits CARBLIM strictly apply at the country level. In other words, countries are not allowed to buy or sell emission permits on international markets. All emission reductions must take place domestically.

- TRD: Emission rights can be traded across borders. There are no restrictions to the eligibility of trading partners and the magnitude of emission trade.

Throughout the simulations, we treat emission limitations as a resource constraint. We then can interpret the shadow price on the emission constraint, i.e. the marginal abatement costs, as the price of emission rights. In the TRD case, there will be an equalization of marginal abatement costs across countries. Revenues from emission permits enter the national accounts in each region.

\section{Summary of Analytical Framework}

\section{A. Model Characteristics}

This section provides a non-technical description of the intertemporal multi-sector, multi-region model underlying our analysis. The detailed algebraic model formulation can be downloaded under ftp://ftp.zew.de/pub/zew-docs/div/contraction.pdf. ${ }^{7}$ The model features 10 regions which are linked through bilateral trade flows. The economic structure of each region consists of 4 production sectors (1 non-energy macro good sector and 3 fossil fuel sectors) whose outputs are demanded by intermediate production, exports, investment and a representative consumer. Table 1 gives an overview of the regional and sectoral aggregation.

Producers and representative consumers behave according to the competitive paradigm, in the sense that they take market prices as given. Consumption and investment decisions are based on rational point expectations of future prices. The representative agent for each region maximizes lifetime utility from consumption which implicitly determines the level of savings. Entrepreneurs choose investment in order to maximize the present value of their firms. Rational expectations in a deterministic model confers clairvoyance on all

\footnotetext{
${ }^{6}$ An alternative form of flexibility, so-called when-flexibility is disregarded in this paper. When-flexibility entails the banking and borrowing of carbon emission rights. A recent analysis of when-flexibility in greenhouse gas abatement is provided by Stephan and Müller-Fürstenberger (2002).
} 
producers and consumers. While this assumption is strong, it seems to be the only consistent approach in a deterministic model (see e.g. Manne and Richels 1992).

Table 1: Overview of sectors and regions

\begin{tabular}{llll}
\hline Sectors & & Regions & \\
\hline Energy & & AFR & Sub-Saharan Africa \\
COA & Coal & CHN & China \\
GAS & Natural gas & IDI & India \\
OIL & Crude oil & LAM & Latin America and the Caribbean \\
Non-Energy & & MEA & Middle East and North Africa \\
ROI & Non-energy macro good aggregate & NAM & North America (USA and \\
& & & Canada) \\
& & PAO & $\begin{array}{l}\text { Pacific OECD (Japan, Australia, } \\
\text { New Zealand) }\end{array}$ \\
& & PAS & Other Pacific Asia \\
& & REC & $\begin{array}{l}\text { Reforming economy countries } \\
\text { (newly independent states of the }\end{array}$ \\
& & & former Soviet Union, Central and \\
& & & Eastern Europe) \\
& & Western Europe \\
\hline
\end{tabular}

In each region production of the non-energy macro good is captured by an aggregate production function which characterizes technology through transformation possibilities on the output side (between production for domestic and export markets) and substitution possibilities on the input side (between alternative combinations of inputs). On the output side production is split between goods produced for the domestic markets and goods produced for the export market subject to a constant elasticity of transformation. On the input side capital, labor and an energy aggregate of fossil fuels trade off with a constant elasticity of substitution (CES). Production of the energy aggregate is described by a CES function which reflects substitution possibilities for different fossil fuels (i.e., coal, gas, and oil). Fossil fuels are produced from fuel-specific resources and the non-energy macro good subject to a CES technology. The elasticities of substitution between the resource inputs and non-energy inputs are calibrated to exogenous supply elasticities for each of the fossil fuels. The resource supplies are calibrated to baseline estimates of fossil fuel production as given be the IIASA/WEC Global Energy Perspectives (IIASA 1998).

\footnotetext{
${ }^{7}$ A disk including all the data and the programs for the replication of our results can be obtained from the authors on request. The model is implemented in GAMS (Brooke et al. 1996) using MPSGE (Rutherford 1999) and solved with PATH (Dirkse and Ferris 1995).
} 
The representative household in each region chooses to allocate lifetime income across consumption in different time periods in order to maximize lifetime utility. In each period households face the choice between current consumption and future consumption, which can be purchased via savings. That is, consumption and the level of savings are endogenously determined in each period by intertemporal utility maximization. The trade-off between current consumption and savings is given by a constant intertemporal elasticity of substitution. Households demand an aggregate consumption good, which is a CES composite of the non-energy macro good and a household-specific energy aggregate.

Output is divided between consumption (incl. exports and intermediate demand) and investment. The latter augments the depreciated capital stock in the next period. Investment takes place as long as the marginal return on investment equals the marginal cost of capital formation. The rates of return are determined by a uniform and endogenous world interest rate such that the marginal productivity of a unit of investment and marginal utility of a unit of consumption is equalized within and across countries.

Following Armington (1969), domestic, imported and exported varieties of the nonenergy goods are distinguished by origin. The Armington aggregation function provides a constant elasticity of substitution between domestic and imported varieties for the non-energy good for all buyers in the domestic market. With respect to trade in energy, fossil fuels from different regions are treated as perfect substitutes, which implies that we use net trade data with no cross-hauling. International capital flows reflect borrowing and lending at the world interest rate, and are endogenous subject to an intertemporal balance of payments constraint: there is no change in net indebtedness over the entire model horizon.

In each region there are backstop technologies for producing the industrial energy aggregate and the household energy aggregate. The backstop technology defines the price for a carbon free energy source in infinite supply (e.g. photovoltaic, fuel cells) and provides an upper limit on the marginal costs of reducing carbon emissions. In each region the backstops are produced employing the region's non-energy macro good.

\section{B. Parameterization}

Benchmark data are used to calibrate parameters of the functional forms from a given set of quantities, prices and elasticities. Data from four different sources are combined to yield a consistent benchmark data set: 
- GTAP database (McDougall et al. 1998): GTAP includes detailed input-output tables for 45 regions and 50 production sectors as well as a world trade matrix with bilateral trade flows for all sectors and regions.

- IEA energy balances and energy prices/taxes (IEA 1996): IEA provides statistics on physical energy flows and energy prices for industrial and household demands.

- IIASA/WEC (IIASA 1998): IIASA/WEC makes projections on the future development of world GDP and fossil fuel production for the 21 st century differentiated by countries.

- World Population Prospects (UN 1996): This source provides data on population growth till 2050 for 194 countries plus summary groups.

We replace GTAP's aggregate input-output monetary values for energy supply and demand with physical energy flows and energy prices as given in IEA's energy statistics. This "bottom-up" calibration of energy demands and supplies yields sector-specific and energyspecific $\mathrm{CO}_{2}$ coefficients. The advantage is that marginal abatement cost curves and hence the cost evaluation of emission constraints are based on actual energy flows rather than aggregate monetary data, which strengthens the credibility of the quantitative results.

Dynamic models in applied CGE analysis are often calibrated to a steady state growth path in which all physical quantities grow at exogenous rates. ${ }^{8}$ In our analysis we incorporate the IIASA/WEC projections on non-uniform potential growth rates for GDP and fossil fuel production across countries. The exogenous assumptions on fossil fuel production for our business-as-usual $(B A U)$ scenario imply a reference emission level for the world as a whole. At the country level, the $B A U$ emission trajectory determines the extent to which restrictions of emission entitlements as prescribed by $C E P, E P C$, and $C O V$ bind economies in the future. 9

\section{Results}

\section{A. Per Capita Endowments}

Table 2 reports the per capita endowments over time for the three entitlement rules. We first consider the actual emission profile as of 2000. It shows a tremendous dispersion, ranging from 0.21 tons for Africa to 5.23 tons for North America.

In the scenario $C E P$, the regional per capita emission rights by 2050 range from 0.06 tons for Africa to 3.27 tons for North America, i.e. a North American's emission rights exceed

\footnotetext{
${ }^{8}$ The virtue of the steady state calibration is that the amount of exogenous information which goes beyond the explanatory scope of the model is kept at a minimum.
} 
those of an African by more than a factor of 50. This ratio for 2050 is more than twice the current ratio. In general, the $C E P$ rule implies a further increase of the already large inequities of per capita emissions between industrialized and developing countries. The reason for this result is the strong population growth projected for many of the developing countries, especially in Africa and the Middle East.

Table 2: Per capita emission endowments by region for alternative entitlement rules (in tons of carbon)

\begin{tabular}{|c|c|c|c|c|c|c|}
\hline & 2000 & 2010 & 2020 & 2030 & 2040 & 2050 \\
\hline \multicolumn{7}{|c|}{ Scenario $C E P$} \\
\hline AFR & 0.21 & 0.19 & 0.14 & 0.11 & 0.08 & 0.06 \\
\hline $\mathrm{CHN}$ & 0.72 & 0.78 & 0.66 & 0.56 & 0.47 & 0.39 \\
\hline IDI & 0.22 & 0.23 & 0.19 & 0.16 & 0.13 & 0.10 \\
\hline LAM & 0.58 & 0.61 & 0.50 & 0.41 & 0.33 & 0.27 \\
\hline MEA & 0.55 & 0.51 & 0.37 & 0.27 & 0.20 & 0.15 \\
\hline NAM & 5.23 & 5.84 & 5.11 & 4.43 & 3.84 & 3.27 \\
\hline PAO & 2.87 & 3.32 & 3.05 & 2.78 & 2.47 & 2.16 \\
\hline PAS & 0.68 & 0.71 & 0.60 & 0.50 & 0.41 & 0.34 \\
\hline REC & 1.83 & 2.06 & 1.81 & 1.56 & 1.32 & 1.10 \\
\hline WEU & 2.75 & 3.23 & 2.97 & 2.70 & 2.38 & 2.07 \\
\hline WORLD & 1.07 & 1.11 & 0.91 & 0.75 & 0.60 & 0.48 \\
\hline \multicolumn{7}{|c|}{ Scenario $E P C$} \\
\hline All regions (WORLD) & 1.07 & 1.11 & 0.91 & 0.75 & 0.60 & 0.48 \\
\hline \multicolumn{7}{|c|}{ Scenario $\mathrm{COV}$} \\
\hline AFR & 0.21 & 0.20 & 0.27 & 0.34 & 0.41 & 0.48 \\
\hline $\mathrm{CHN}$ & 0.72 & 0.83 & 0.74 & 0.66 & 0.57 & 0.48 \\
\hline IDI & 0.22 & 0.23 & 0.29 & 0.36 & 0.42 & 0.48 \\
\hline LAM & 0.58 & 0.60 & 0.57 & 0.54 & 0.51 & 0.48 \\
\hline MEA & 0.55 & 0.52 & 0.51 & 0.50 & 0.49 & 0.48 \\
\hline NAM & 5.23 & 5.66 & 4.36 & 3.07 & 1.78 & 0.48 \\
\hline PAO & 2.87 & 3.26 & 2.56 & 1.87 & 1.18 & 0.48 \\
\hline PAS & 0.68 & 0.73 & 0.67 & 0.60 & 0.54 & 0.48 \\
\hline REC & 1.83 & 2.10 & 1.70 & 1.29 & 0.89 & 0.48 \\
\hline WEU & 2.75 & 3.15 & 2.48 & 1.82 & 1.15 & 0.48 \\
\hline WORLD & 1.07 & 1.11 & 0.91 & 0.75 & 0.60 & 0.48 \\
\hline
\end{tabular}

\footnotetext{
${ }^{9}$ See Böhringer et al. (2000) on the implications of alternative baseline assumptions for the magnitude and distribution of abatement costs.
} 
The EPC scenario entails that the current inequality in per capita emissions be abolished within less than 10 years, i.e. by 2010 . This scenario implies that the developing regions get emission rights in excess of their current emissions, while industrialized countries have to cut back their emissions strongly or else - under tradability - must buy substantial amounts of emission rights. As the extreme example, an African by 2010 would have the right to emit five times as much as she or he currently does whereas a North American would be entitled to emit less than 20 percent of current emissions.

These figures illustrate the potential drawbacks of both the CEP and the EPC scenarios. While the former places a huge long-term burden on the developing countries, the latter confronts the industrialized countries with tremendous short-term adjustment requirements. The $C O V$ rule avoids these drawbacks. In this scenario, all regions, except for Africa and India, are facing decreasing per capita emission rights in the long term, but the time path entails neither abrupt changes in the beginning nor huge inequalities towards the end.

\section{B. Effective Cutback Requirements and Marginal Abatement Costs}

The economic effects of carbon abatement depend on the effective cutback requirements, i.e. emission reductions relative to the $B A U$ path of emissions. The effective cutback requirements by region are reported in Table 3. Negative entries indicate that the respective emission constraint is not binding.

In the CEP scenario, all regions face binding carbon constraints from 2020 onwards. The percentage cutback rates are rather uniform across regions because differences in emission entitlements closely reflect the differences in $B A U$ emissions. By 2050, cutback rates are between 59 and 64 percent.

Under EPC, by contrast, cutback rates are much more dispersed. Some regions are not facing binding constraints at all, but are entitled to emit more than they are expected to under $B A U$. This is the case for AFR, IDI and MEA over the whole time horizon and for CHN, LAM, and PAS over the first few decades.

In the COV scenario, the cutback rates by 2050 are the same as in the EPC case, but different at earlier dates. AFR, IDI and MEA again have abundant emission rights over the entire time horizon, but the percentage of unused rights in the first decades is much smaller than under EPC. For CHN, LAM and PAS no abundant rights occur at all.

At the global level, surplus carbon rights under EPC as well as $C O V$ imply that emissions by 2050 are roughly 10 percent below the IPCC target (see Figure 1). 
Table 3: Effective cutback requirements ( $\%$ from $B A U$ )

\begin{tabular}{|c|c|c|c|c|c|}
\hline & 2010 & 2020 & 2030 & 2040 & 2050 \\
\hline \multicolumn{6}{|c|}{ Scenario $C E P$} \\
\hline AFR & - & 23 & 39 & 51 & 61 \\
\hline $\mathrm{CHN}$ & - & 26 & 42 & 55 & 64 \\
\hline IDI & - & 23 & 39 & 51 & 60 \\
\hline LAM & - & 21 & 38 & 50 & 59 \\
\hline MEA & - & 22 & 40 & 52 & 61 \\
\hline NAM & - & 20 & 37 & 50 & 61 \\
\hline PAO & - & 21 & 38 & 52 & 63 \\
\hline PAS & - & 24 & 41 & 53 & 62 \\
\hline REC & - & 25 & 43 & 55 & 63 \\
\hline WEU & - & 21 & 37 & 50 & 61 \\
\hline \multicolumn{6}{|c|}{ Scenario $E P C$} \\
\hline AFR & -469 & -392 & -331 & -269 & -215 \\
\hline $\mathrm{CHN}$ & -34 & 4 & 28 & 46 & 58 \\
\hline IDI & -384 & -269 & -190 & -130 & -85 \\
\hline LAM & -86 & -47 & -16 & 8 & 26 \\
\hline MEA & -115 & -89 & -63 & -44 & -26 \\
\hline NAM & 80 & 85 & 89 & 92 & 94 \\
\hline PAO & 66 & 76 & 83 & 88 & 92 \\
\hline PAS & -53 & -14 & 14 & 32 & 46 \\
\hline REC & 47 & 63 & 73 & 80 & 84 \\
\hline WEU & 65 & 75 & 82 & 87 & 91 \\
\hline \multicolumn{6}{|c|}{ Scenario $\mathrm{COV}$} \\
\hline AFR & - & -44 & -95 & -151 & -215 \\
\hline CHN & - & 22 & 37 & 49 & 58 \\
\hline IDI & - & -18 & -38 & -59 & -85 \\
\hline LAM & - & 8 & 16 & 22 & 26 \\
\hline MEA & - & -5 & -9 & -17 & -26 \\
\hline NAM & - & 30 & 55 & 76 & 94 \\
\hline PAO & - & 33 & 58 & 77 & 92 \\
\hline PAS & - & 17 & 30 & 39 & 46 \\
\hline REC & - & 31 & 54 & 70 & 84 \\
\hline WEU & - & 32 & 57 & 75 & 91 \\
\hline
\end{tabular}

The occurrence of unused emission rights under the EPC scheme and, to a lesser extent, under the $C O V$ scheme is likely to increase the global economic adjustment costs as compared to the $C E P$ scheme, unless emission rights are internationally tradable (i.e. surplus 
emission rights will be sold). Conversely, the economic benefit from tradability can be expected to be more pronounced under $C O V$ and, particularly, under $E P C$ than under $C E P$. We will return to this logic below.

Figure 1 visualizes the global carbon trajectories for business-as-usual $(B A U)$ vis-à-vis the overall carbon entitlements (CARBLIM) and the actual emission path for the no-trade case under scenarios $C E P, E P C$ and $C O V$. Under $B A U$, global emissions increase from roughly $6 \mathrm{Gt}$ carbon in 2000 to $11.5 \mathrm{Gt}$ carbon in 2050 . This $B A U$ trajectory is in line with the IIASA/WEC A1-scenario (IIASA 1998). By 2050, the global carbon limit of $4.4 \mathrm{Gt}$ as suggested by the IPCC is more than 60 percent below $B A U$ emissions which makes clear the dramatic adjustment requirements towards less carbon-intensive production and consumption patterns. For $C E P$, there are no surplus emission rights in the no-trade case. The $C E P$ trajectory, therefore, coincides with the CARBLIM trajectory. As explained above, emissions under $C O V$ and EPC may fall short of the overall CARBLIM entitlements to the extent that several regions do not face a binding carbon constraint.

Figure 1: Carbon emission trajectories

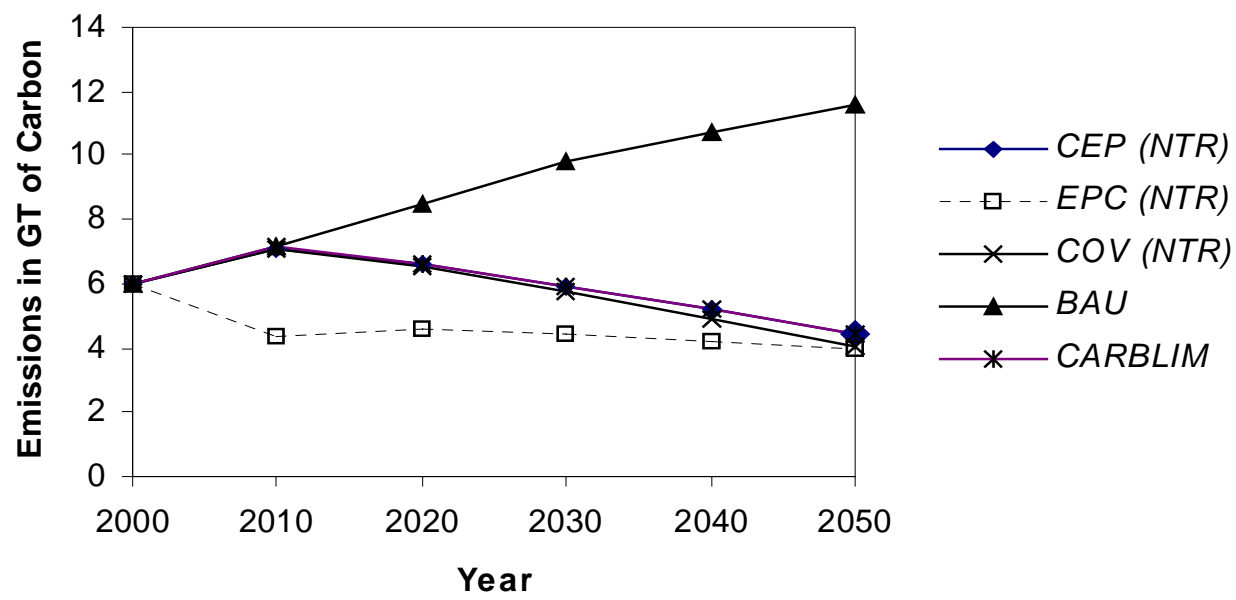

At the regional level, the effective cutback requirements constitute a key determinant for the magnitude of marginal abatement costs in the no-trade case (NTR). The latter, in turn, determines which countries will be sellers or buyers of emission rights when emission rights can be traded across regions (TRD): Countries whose marginal abatement costs under NTR are below the global carbon price (labeled WORLD in Figures 2-4 below) will sell emission rights and abate more emissions. Conversely, countries whose marginal abatement costs are above the global price will buy emission rights and abate less emissions.

The marginal abatement costs under the various emission entitlement schemes are shown in Figures 2-4. While the global marginal abatement costs under TRD are almost 
independent of the specific entitlement scheme, the regional marginal abatement costs under $N T R$ and, hence, the distribution of buyers and sellers, if trade got implemented, is much influenced by the entitlement rule.

In the CEP case, the dispersion of marginal abatement costs across regions is relatively moderate, ranging from 330 \$US to 655 \$US by 2050. AFR, CHN, IDI and REC have costs below the global carbon price and, therefore, will sell emission rights to the other regions, i.e. LAM, MEA NAM, PAO, PAS, and WEU. The relatively narrow range of marginal abatement costs across regions under $C E P$ explains why emissions trading has rather small effects: The group of permit buyers only emit 4 percent more than they would under $N T R$ whereas the group of permit sellers just emit 6 percent less as compared to the NTR case.

In the EPC scenario, marginal abatement costs by 2050 range from 0 \$US up to 1600 \$US. Industrialized countries (REC and OECD regions NAM, WEU, PAO) face relatively high effective abatement requirements and, therefore, have high marginal abatement costs. On the other hand, EPC imposes rather modest abatement requirements on CHN, LAM, and PAS which translates into relatively low marginal abatement costs rendering these regions to permit sellers in the TRD case. The regions AFR, IDI and MEA - not facing any binding constraint over the whole time horizon - have zero abatement costs and will also be sellers. Emissions trading under EPC induces large changes in the regional pattern of emissions compared to purely domestic abatement. While the group of permit buyers increase emissions by more than the double of their aggregate NTR emission level, the group of sellers only emit roughly 70 percent of their NTR emissions. It is important to note that the large increase of emissions within buyer regions is not only accommodated by additional reduction efforts on behalf of the seller regions but also by the use of previous surplus emissions in regions AFR, IDI, and MEA (as well as regions CHN, LAM, and PAS within the first few decades).

The same range of marginal abatement costs by 2050 and the same buyer-seller configuration as in the EPC scenario arises in the $C O V$ scenario. The implications of emissions trading on the regional reallocation of emissions are, however, significantly less pronounced than in the EPC case: The possibility to buy cheaper abatement abroad makes the group of permit buyers emit 1.3 as much as they would under NTR whereas the group of permit sellers decreases emissions to roughly 80 percent of their NTR emission level. The reason for the differences between $E P C$ and $C O V$ becomes obvious from Figures 3 and 4.

While marginal abatement costs across regions coincide towards 2050 for both scenarios they differ a lot in the preceding decades. The regional dispersion is much more distinct under $E P C$ than under $C O V$ providing more scope for international emissions trading. 
Section $4 \mathrm{C}$ below will confirm the economic intuition that the magnitude of changes in regional emissions induced by emissions trading is a natural indicator for the achieved economic benefits from where-flexibility. The larger these changes are, the higher the potential welfare gains from emissions trading.

Figure 2a: Marginal abatement costs under NTR below global TRD permit price (WORLD) for entitlement scheme CEP (seller regions)

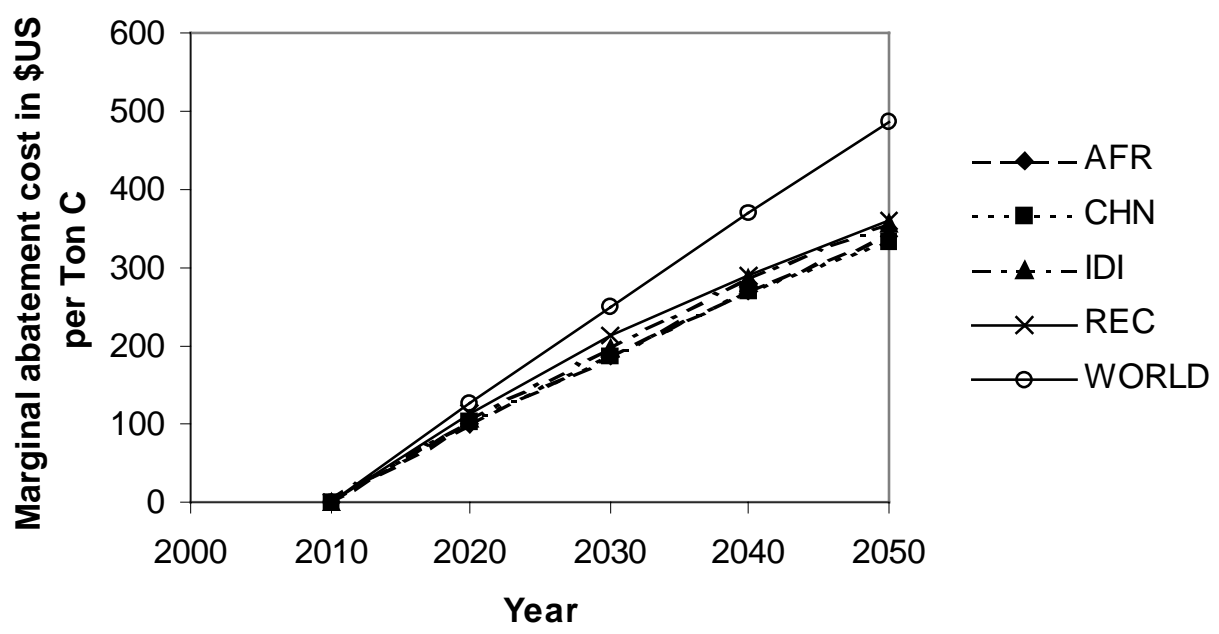

Figure 2b: Marginal abatement costs under NTR above global TRD permit price (WORLD) for entitlement scheme CEP (buyer regions)

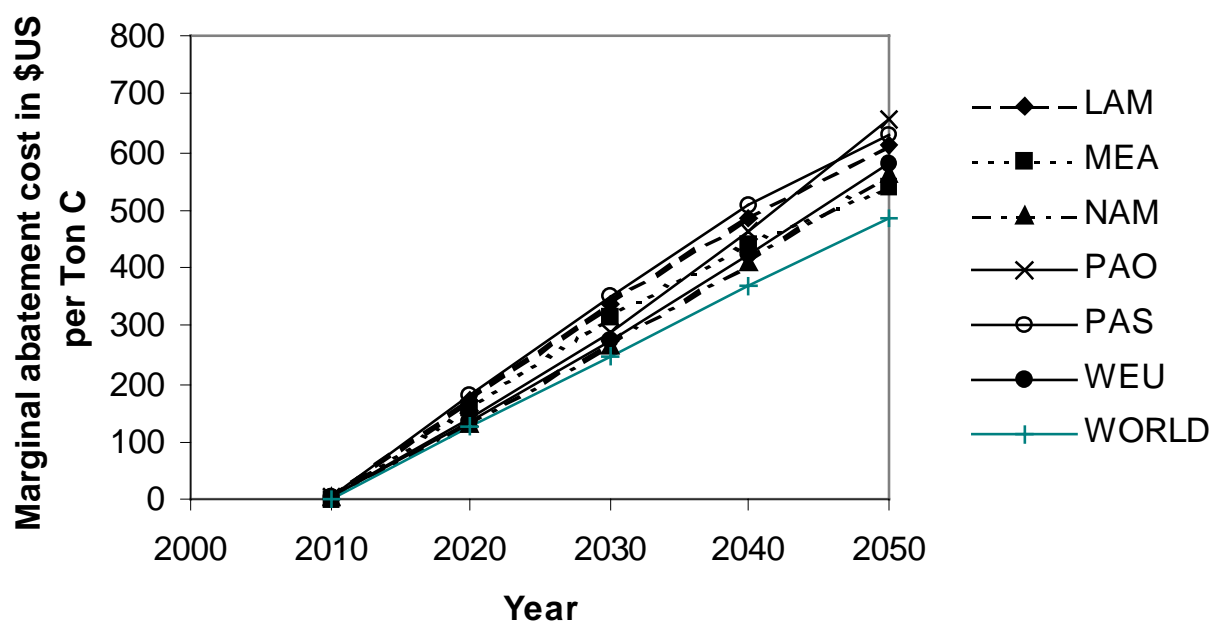


Figure 3a: Marginal abatement costs under NTR above global TRD permit price (WORLD) for entitlement scheme $E P C$ (seller regions)

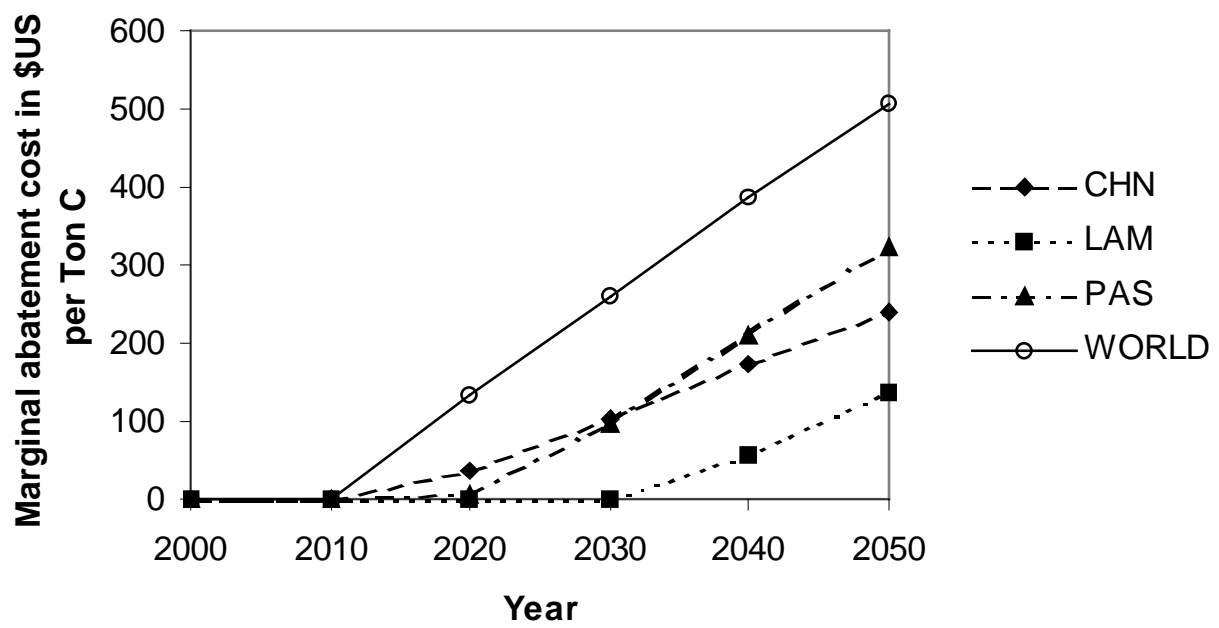

Figure 3b: Marginal abatement costs under NTR below global TRD permit price (WORLD) for entitlement scheme $E P C$ (buyer regions)

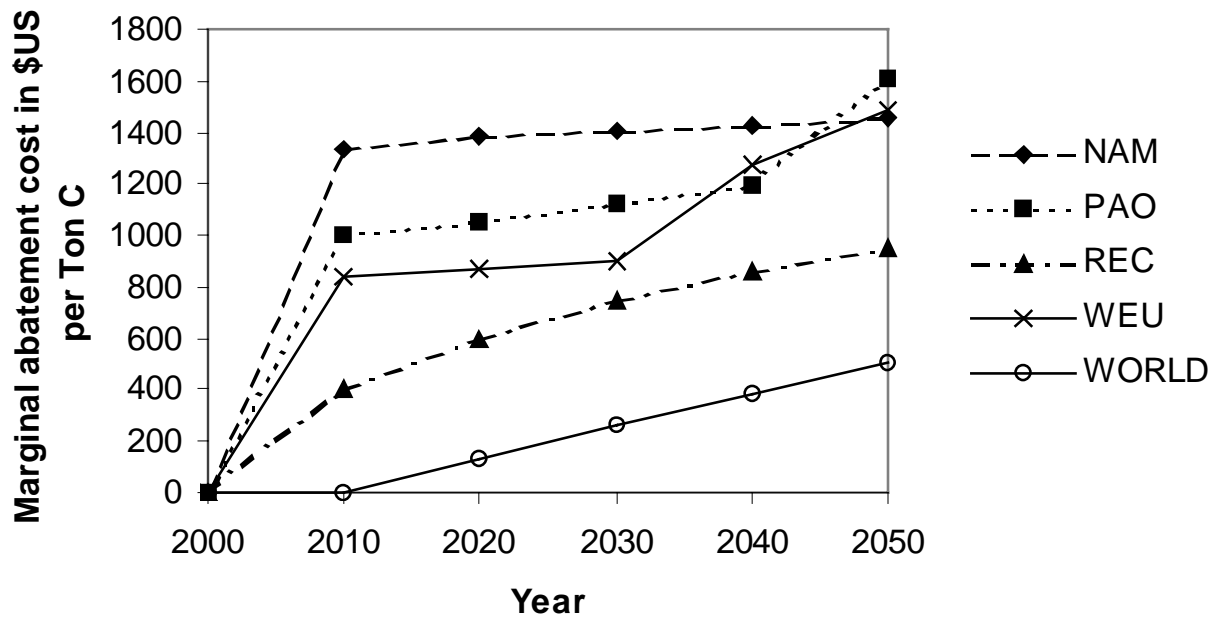

N.B.: IDI, MEA, and AFR are sellers without any binding carbon constraint. 
Figure 4a: Marginal abatement costs under NTR above global TRD permit price (WORLD) for entitlement scheme $\operatorname{COV}$ (seller regions)

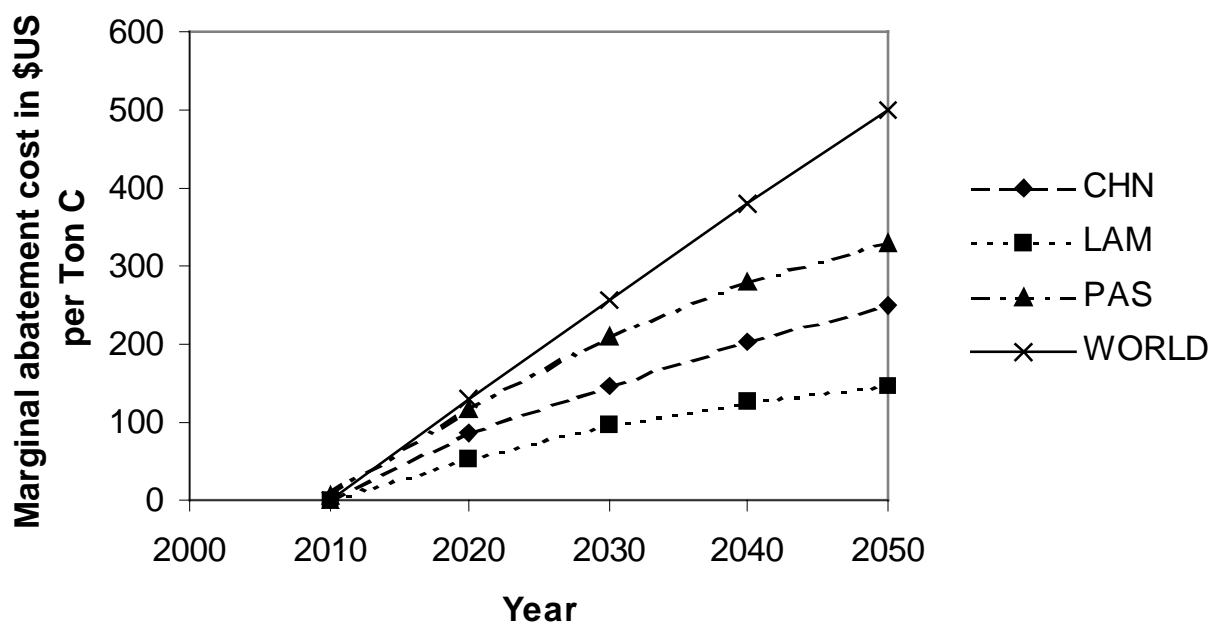

Figure 4b: Marginal abatement costs under NTR above global TRD permit price (WORLD) for entitlement scheme $C O V$ (buyer regions)

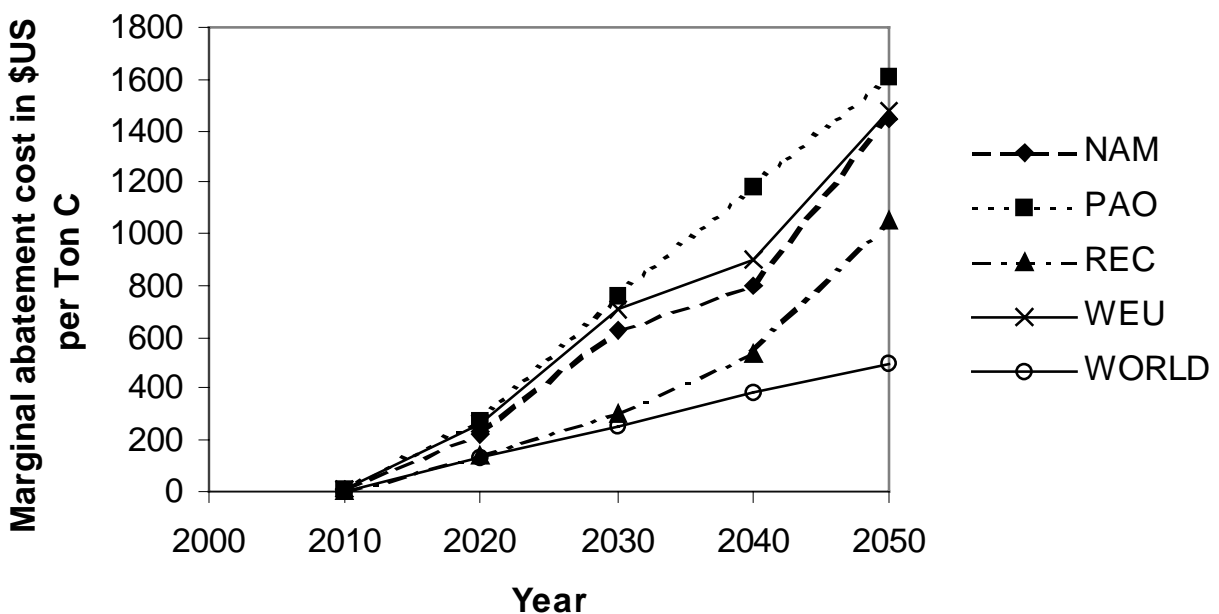

N.B.: IDI, MEA, and AFR are sellers without any binding carbon constraint. 


\section{Welfare Effects}

It is the view taken in this paper that the acceptability of alternative permit allocation schemes depends on their implications for economic welfare (see footnote 3). We measure welfare changes by the Hicksian equivalent variation $(H E V)$ in lifetime income discounted to the year 2000. The welfare changes that arise from carbon abatement under the various emission entitlement schemes are reported in Table 4 for the NTR and TRD case.

Table 4: HEV in lifetime income (\% change from $B A U)-N T R$ versus $T R D$

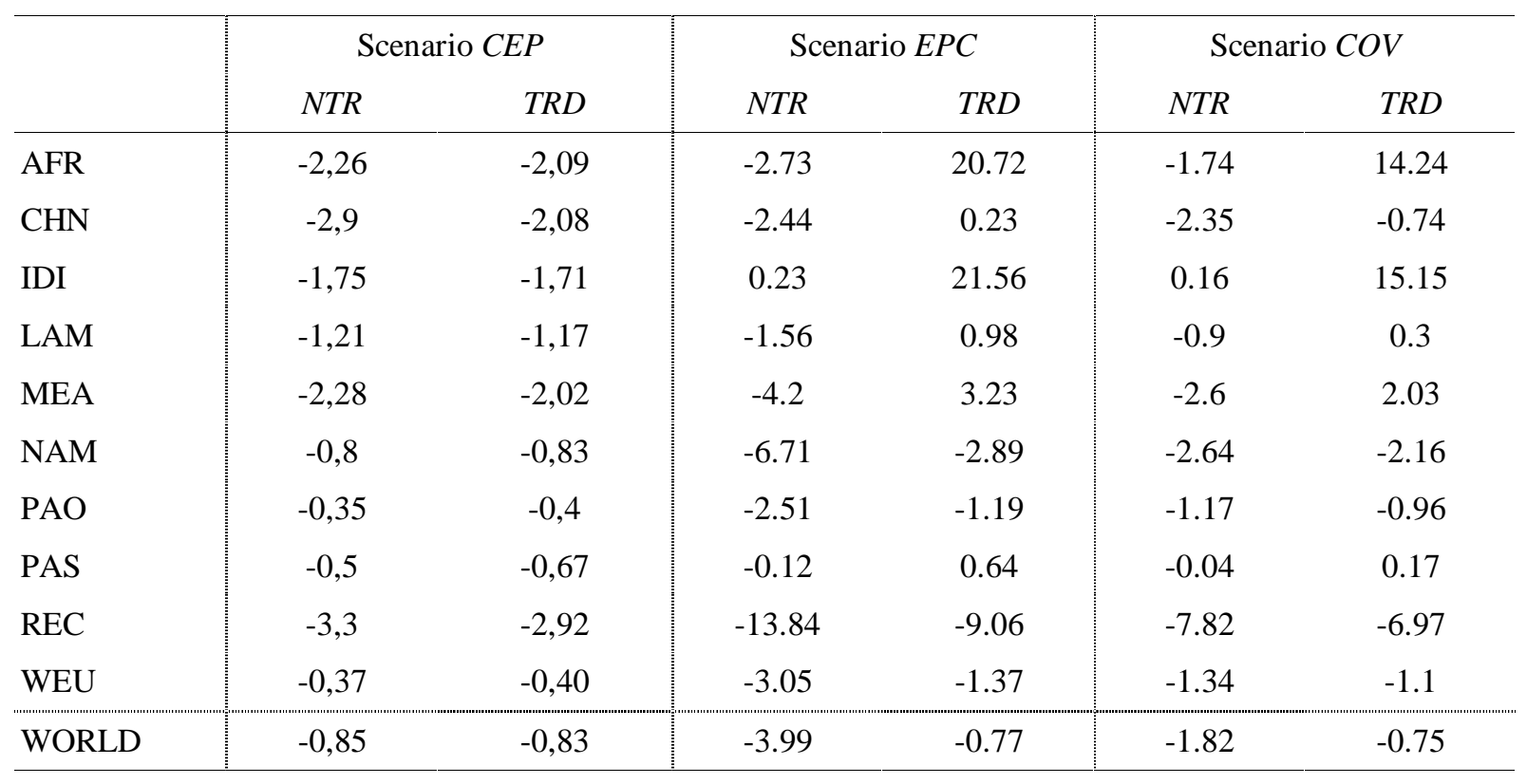

Before starting the interpretation of results, it is useful to consider the factors which determine the magnitude of welfare changes in a particular region. A major determinant of a region's abatement costs and ensuing welfare losses is its effective cutback requirement. Larger reduction in carbon emissions as a percentage of $B A U$ emissions leads to larger abatement costs. However, emission abatement in large open economies will not only affect the allocation of domestic resources but also change international market prices. The change in international prices implies an indirect secondary burden or benefit for all countries which can significantly alter the primary economic implications of the domestic abatement policy. ${ }^{10}$ Depending on its initial trade patterns a region will gain or lose from these international spillovers, i. e. changes in its terms of trade.

With respect to carbon abatement and our sectoral disaggregation, it is useful to distinguish spillovers from (a) fossil fuel markets: A larger cutback in global fossil fuel

\footnotetext{
${ }^{10}$ See Böhringer and Rutherford (2001) for a decomposition procedure of primary and secondary effects.
} 
consumption depresses the international prices of fossil fuels ${ }^{11}$, and (b) non-energy markets: Due to product heterogeneity associated with the Armington assumption for non-energy macro good trade, countries are able to pass on an increase in production costs to other countries. Whether a country will experience a terms-of-trade loss or gain on the macro good markets depends on its initial trade shares and elasticities (of export supply and import demand) as well as differences in the cost changes of macro good production induced by the abatement scenario.

Terms-of-trade effects explain why a country can experience a welfare loss even if it does not face a binding emission constraint, as is the case for some countries in our EPC and $C O V$ scenarios. As it will be seen, they also can influence considerably the primary benefits from international emissions trading.

In the $C E P$ scenario without emissions trading, all countries face a binding emission constraint and experience a loss in welfare which ranges from roughly $1 / 3$ percent for WEU and PAO to more than 3 percent for REC. Differences in welfare losses not only depend on differences in the cutback requirements as reported in Table 3 but also on implied terms-oftrade effects. On a worldwide scale, the welfare loss amounts to 0.85 percent. Under TRD, the global welfare loss remains more or less unchanged ( 0.83 percent): Since the dispersion of abatement costs is not very large under the CEP scheme, the overall benefits from lower abatement costs arising under TRD are relatively small. Nevertheless, countries with large losses under NTR, i.e. REC and CHN, now fare significantly better. On the other hand, the welfare losses of PAO, WEU, NAM, and, particularly, PAS get enhanced which indicates that emissions trading does not produce a Pareto improvement over NTR for the CEP scenario.

The result that emissions trading does not lead to a Pareto improvement is a clear instance of terms-of-trade effects: Although it is known that - in the absence of second-best effects - emissions trading must improve global efficiency, there is no guarantee - a priori that every region will benefit from emissions trading. The reason behind this ambiguity are changes in the terms of trade which - contrary to the wide-spread partial equilibrium approach in environmental policy analysis - are taken into account in our general equilibrium framework. ${ }^{12}$ In the $C E P$ scenario under $T R D$, portions of the abatement burden are shifted to

\footnotetext{
${ }^{11}$ Obviously, a region which imports fossil fuels will benefit from the contraction of world fuel consumption whereas a country which exports fossil fuels will suffer.

${ }^{12}$ In terms of primary effects (i. e. without induced changes in international prices) all countries will benefit from carbon trade. Secondary terms-of-trade effects, however, could offset or enhance the primary benefit from trading carbon across domestic borders. Obviously, the prospects that the unambiguous primary gains from emissions trading dominate the ambiguous secondary terms-of-trade effects depend on the initial permit allocation. The more countries deviate in marginal abatement costs for the NTR case, the higher are the global efficiency gains and - ceteris paribus - the associated gains at the country level.
} 
countries which are major suppliers of import goods for PAS, PAO, NAM and WEU. The import prices of the latter countries' increase. This more than offsets their primary benefit from emissions trading due to reduced direct abatement costs.

The welfare effects are much different when we consider the $E P C$ scheme. The main finding is that, in the absence of emissions trading, the global welfare cost is higher than that under CEP by almost a factor of five. This is the result of two partial effects. First, even though the global carbon cap is the same as under $C E P$, the respective region-specific cap is not binding for some of the developing countries. Consequently, the effective global carbon emissions are lower under $E P C$ than under $C E P$, and the global economy faces a stronger adjustment requirement. Second, cutback rates under EPC are high for the industrialized regions, even in the short term, requiring large structural adjustments. This implies very high costs for the industrialized world as compared to the CEP scheme where emission entitlements deviate much less from the $B A U$ emission requirements.

A striking insight is that AFR and MEA, although not facing binding emission constraints over the entire time span, experience significant welfare losses which even succeed their adjustment costs in the apparently more restrictive CEP case. The reason is again to be found in terms-of-trade effects: The imports of these countries become more expensive because of high abatement costs in the supplier countries; in addition, reduced import demand by the industrialized world, whose economic activity and income drops substantially, exerts a downward pressure on the prices of exports from AFR and MEA (in particular, revenues from fossil fuel exports decline). IDI, on the other hand, perceives termsof-trade gains, mainly due to reduced expenditure for fossil fuel imports.

Given the large divergence of marginal abatement costs across countries under the $E P C$ scheme, emissions trading offers huge benefits. When moving from NTR to TRD, the global welfare loss drops from almost 4 percent to 0.77 percent. ${ }^{13}$ In addition, emissions trading is Pareto improving under the EPC scheme. As EPC entails large cross-country differences in marginal abatement costs, the primary efficiency gains from emissions trading are high enough to more than outweigh potentially negative terms-of-trade effects. In addition, emissions trading now implies that all of the developing regions (including $\mathrm{CHN}$ ) actually gain from climate change mitigation, i.e. they improve their economic welfare considerably beyond $B A U$ levels. ${ }^{14}$ For OECD regions (NAM, WEU and PAO) and the

\footnotetext{
${ }^{13}$ Note that the global welfare loss for emissions trading under $E P C$ as well as under $C O V$ is now smaller than under $C E P$ due to income effects incorporated in the general equilibrium framework.

${ }^{14}$ Note that some of these regions do not exploit their carbon budget to the full extent under NTR. Their (shadow) price of emission rights increases dramatically from zero in the NTR case to the world market permit
} 
reforming economy countries (REC) international emissions trading reduces adjustment costs but still leaves them with significant welfare losses. In fact, the losses of industrialized countries for $E P C$ under TRD are much higher than those for $C E P$ under NTR.

Considering the $C O V$ entitlement scheme under NTR, we find the global welfare loss to be much more moderate than under the more extreme EPC allocation but still more than the double of the $C E P$ value. The welfare implications for IDI, MEA and AFR again reveal the importance of international spillovers. Although these regions do not have to undertake domestic abatement, they are affected by abatement action in other countries through changes in international market prices. While IDI slightly gains from international spillovers, MEA and AFR suffer from abatement elsewhere. As under EPC, the regions REC and NAM again have the strongest losses in welfare, but these losses are now much lower because of less stringent effective cutback requirements.

If the $C O V$ entitlement scheme is combined with emissions trading, we find that the global welfare loss is reduced by half. Emissions trading is again universally beneficial as compared to the NTR case, which means that under $C O V$ the primary efficiency gains from emissions trading are still high enough to more than outweigh negative terms-of-trade effects for individual regions. Similar to emissions trading under the EPC entitlement scheme, the developing regions (except for $\mathrm{CHN}$ ) improve their economic welfare beyond $B A U$ levels whereas CHN and the industrialized world (in particular, REC and NAM) still face significant welfare losses.

\section{Discussion and Conclusions}

In assessing our simulation results, it can be concluded that $C E P$ without whereflexibility imposes particularly high welfare losses on REC and on the low developed regions AFR, CHN, IDI and MEA. Emissions trading offers only very limited potential for alleviating their burdens. In addition, emissions trading is in this case not universally (Pareto) superior to a no-trade regime and may therefore be rejected by several regions. Overall, CEP can, thus, be assessed as unacceptable to the developing countries independent of the degree of whereflexibility.

Concerning the EPC scheme, the most outstanding result is that, unless coupled with emissions trading, it entails global welfare costs several times higher than those encountered under the other entitlement rules. The extreme dispersion of marginal abatement costs implied by the EPC arrangement offers a large potential for cost reduction by means of international

price under TRD. In other words: Their abundant emission rights under NTR become a valuable international 
emissions trading. The latter will cut global welfare costs by 80 percent and would provide a Pareto improvement over the corresponding no-trade case. EPC cum emissions trading, however, induces a pronounced dichotomy between the developing countries (including $\mathrm{CHN}$ ) and the industrialized countries in that the former experience welfare gains relative to the doing-nothing $(B A U)$ case, whereas the latter would must carry the burden not only of climate change mitigation but also of large-scale global income redistribution.

In the $C O V$ scenario, it is still true that most developing countries experience a welfare gain relative to $B A U$ if emission entitlements are tradable, but the net transfers involved are much smaller. Emissions trading entails a reduction in global welfare costs by more than half ${ }^{15}$ and is universally superior to the no-trade case. The chief virtue of the COV cum emissions trading arrangement is that it offers the developing countries a substantial incentive for participation in the international climate change mitigation effort. By contrast, CEP entails a further reduction of the already low income of the developing countries (including $\mathrm{CHN}$ ). $E P C$, on the other hand, either implies - in the no-trade case - tremendous global inefficiency, or huge levels of trade in emission rights with associated very large "North-South" transfers. The main problem with $C O V$ is the large welfare loss for REC due to the specific combination of restrictive emission entitlements and adverse terms-of-trade effects from fossil fuel markets, which would likely warrant some assistance from the other industrialized countries.

In addition to the policy perspective, a major methodological insight from our results is that changes in the terms of trade play an important role in assessing the economic implications of alternative frameworks for international greenhouse gas abatement. Terms-oftrade effects may imply that a particular emission entitlement scheme places significant welfare costs even on those countries that do not face binding emission constraints. Therefore, the acceptability of alternative international carbon abatement arrangements cannot be assessed at "face value".

\footnotetext{
resource which provides them with substantial additional net income.

${ }^{15}$ It should be recalled, however, that part of the cost reduction arises because under $C O V$ the global carbon budget is partly unused in the absence of emissions trading. This qualification concerning the virtues of emissions trading applies a fortiori in the EPC case. We maintain, however, that the acceptability of carbon abatement arrangements rests basically on their economic implications, unless the predefined global carbon constraint is violated.
} 


\section{References}

Armington, P.S. (1969), A Theory of Demand for Products Distinguished by Place of Production, IMF Staff Papers 16, 159-178.

Bertram, G. (1992), Tradable emission permits and the control of greenhouse gases, Journal of Development Studies 28 (3), 423-446.

Böhringer, C., J. Jensen and T. F. Rutherford (2000), Energy Market Projections and Differentiated Carbon Abatement in the European Union, in C. Carraro (ed), Efficiency and Equity of Climate Change Policy, Dordrecht: Kluwer Academic Publishers, 199-220.

Böhringer, C., and T. F. Rutherford (2001), Carbon Abatement and International Spillovers, Environmental and Resource Economics (forthcoming).

Brooke, A., D. Kendrick and A. Meeraus (1996), GAMS: A User's Guide, Washington DC: GAMS Development Corp.

Dirkse, S. and M. Ferris (1995), The PATH Solver: A Non-monotone Stabilization Scheme for Mixed Complementarity Problems, Optimization Methods \& Software, 5, 123-156.

Global Commons Institute (1997), Contraction and Convergence: A Global Solution to a Global Problem, http://www.gn.apc.org/gci/contconv/cc.html.

Grubb, M. (1995), Seeking Fair Weather: Ethics and the International Debate on Climate Change, International Affairs 71, 463-496.

Grubb, M. and J. Sebenius (1992), Participation, Allocation, and Adaptability in International Tradable Emission Permit Systems for Greenhouse Gas Control, in: OECD (ed.), Climate Change: Designing a Tradable Permit System, Paris.

Houghton, J.J. et al. (eds.) (1996), Climate Change 1995 - The Science of Climate Change, Cambridge University Press.

IEA (1996), International Energy Agency, Energy Prices and Taxes, Energy Balances of OECD and Non-OECD Countries, Paris: IEA publications.

IIASA (1998), IIASA/WEC Global Energy Perspectives, http://www.iiasa.ac.at

Kverndokk (1995), Tradable $\mathrm{CO}_{2}$ emission permits: Initial distribution as a justice problem, Environmental Values 4, 129-148.

Lindbeck, A. (1983), The Recent Slowdown of Productivity Growth, Economic Journal, 1983.

Manne, A.S. and R.G., Richels, (1992), Buying Greenhouse Insurance: The Economic Costs of CO2 Emission Limits, Cambridge, MIT Press.

McDougall, R. A, A. Elbehri and T. P. Truong. (1998), Global Trade, Assistance and Protection: The GTAP 4 Data Base, Center for Global Trade Analysis, Purdue University, West Lafayette.

Rose, A., B. Stevens, J. Edmonds and M. Wise (1998), International equity and differentiation in global warming policy, Environmental and Resource Economics, 12, 25-51.

Rutherford, T. F. (1999), Applied General Equilibrium Modeling with MPSGE as a GAMS Subsystem: An Overview of the Modeling Framework and Syntax, Computational Economics, 14, 1-46.

Shue, H. (1993), Subsistence Emissions and Luxury Emissions, Law and Policy 15, 39-59.

Stephan, G. and G. Müller-Fürstenberger, G. (2002), Does Distribution Matter? When-Flexibility and Pareto Efficiency in Greenhouse Gas Abatement, in: C. Böhringer, A. Löschel (eds.), Empirical Modeling of the Economy and the Environment, ZEW Economic Studies, Heidelberg, Physica. 
UN (1996), United Nations, World Population Prospects: The 1996 Revision, New York.

UNEP (2001), United Nations Environmental Program, Climate Change 2001: Mitigation, Working Group III, Third Assessment Report, Section 1.3.1.

Welsch, H. (1993), A CO 2 Agreement Proposal with Flexible Quotas, Energy Policy 21, 748-756.

Young, H.P. and A. Wolf (1992), Global Warming Negotiations: Does Fairness Count?, The Brookings Review 10. 